\title{
Oral health status and the occurrence and clinical course of myocardial infarction in hospital phase: A case-control study
}

\author{
Beata Wożakowska-Kapłon ${ }^{1,2}$, Monika Włosowicz ${ }^{1}$, \\ Iwona Gorczyca-Michta ${ }^{2}$, Renata Górska ${ }^{3}$ \\ ${ }^{1}$ Faculty of Health Sciences, The Jan Kochanowski University, Kielce, Poland \\ ${ }^{2} 1^{\text {st }}$ Clinical Department of Cardiology, Swietokrzyskie Cardiology Center, Kielce, Poland \\ ${ }^{3}$ Department of Peridontology, Institute of Dentistry, Medical University of Warsaw, Poland
}

\begin{abstract}
Background: Periodontitis may contribute to destabilization of atherosclerotic plaque leading to acute coronary syndrome and myocardial infarction (MI). The aim of the paper was to evaluate the state of the oral cavity and test the association between chosen parameters of acute, hospital phase MI in patients aged 60 and younger.

Methods: We examined patients with acute MI, age 60. Control group consisted of matched group of patients with stable angina. Patients enrolled in the study underwent dental, cardiovascular and biochemical examination. Left ventricular ejection fraction (LVEF) was measured during echocardiographic examination, intima-media thickness (IMT) was assessed by ultrasonographic examination at the same time.
\end{abstract}

Results: The case group included 112 hospital patients with acute MI. Patients with acute MI were characterized by higher level of cardiovascular disease risk factors and poor oral health status in comparison to the control group. There was higher prevalence of edentulousness $(p=0.0039)$ and advanced periodontal disease $(A P D)(p<0.0001)$ in the case group than in the control group. Patients with edentulousness and APD were characterized by the highest levels of fibrinogen, interleukine-6, tumor necrosis factor- $\alpha$, increased IMT and numerous atherosclerotic plaques. Logistic regression analysis revealed association between biomarkers of myocardial injury, LVEF and chosen periodontal parameter (API, CAL, PDI, BI) and edentulousness.

Conclusions: Poor oral health status, especially periodontal disease may influence on the occurrence and clinical course of MI. (Cardiol J 2013; 20, 4: 370-377)

Key words: periodontal disease, atherosclerosis, myocardial infarction

\section{Introduction}

The appearance of periodontal diseases (PD), which cause extensive inflammatory processes, can develop increased susceptibility to vascular illnesses based on atherosclerosis. Periodontal pathogens affect organism directly by damaging the vascular endothelium and indirectly by activating hypercytokinemia (inflammatory-cytokine storm) $[1,2]$. The important role in this process

\footnotetext{
Address for correspondence: Prof. Beata Wożakowska-Kapłon, $1^{\text {st }}$ Clinical Department of Cardiology, Swietokrzyskie Cardiology Center, ul. Grunwaldzka 45, 25-736 Kielce, Poland, tel: +48 4136 71 510, fax: +48 413671 510,

e-mail: bw.kaplon@poczta.onet.pl
}

Received: 22.07.2012 Accepted: 14.12.2012 
is played by bacterial lipopolysaccharydes (LPS), which mainly originate from periodontal bacteria. Monocytes in contact with LPS produce significantly more inflammatory mediators such as: tumor necrosis factor-alpha (TNF- $\alpha$ ), prostaglandin E2 (PGE-2), interleukin-1 $\beta$ (IL-1 $\beta$ ) and proteolytic enzymes - matrix metalloproteinases (MMP) [3]. In the course of chronic periodontitis higher level of TNF- $\alpha$ and IL- 6 are found in the gingival crevicular fluid. These cytokines not only exert destructive effect on the periodontium but also play essential role in the pathogenesis of arteriosclerosis and cardiovascular diseases (CAD) [4]. Cytokines in liver stimulate production of acute-phase proteins, among other C-reactive proteins (CRP). In the course of PD higher concentration of CRP is recorded. CRP is the marker of chronic inflammation, thrombotic risk and one of the most important exponents of increased cardiovascular risk in general population [5]. It was stated that, compared to the healthy subjects, the level of CRP was 2-fold higher in patients with heart disease or with periodontitis and 3-fold higher when both conditions appeared simultaneously. The increased $\mathrm{CRP}$ is recognized as an independent risk factor for occurrence of acute coronary syndromes (ACS) and acute myocardial infarction (MI) [6]. The presence of inflammatory mediators such as: IL-1, IL-6, TNF- $\alpha$, CRP, fibrinogen and MMP-9, which derive from inflammable periodontium, can occasionally destabilize the arteriosclerotic plaque and cause remote obturation of small arterial vessel - the main mechanism of cardiovascular incidents [7]. The increased concentration of fibrinogen is associated with the increased aggregation of erythrocytes, and with the increased viscosity and resistance in microcirculation. It was proven that in coronary diseases fibrinogen is a stronger risk factor than cholesterol. Fibrinogen and CRP are markers of the systemic inflammatory response and they can be used to assist risk of acute atherosclerotic complications, for instance ACS [8]. A correlation between periodontitis and concentration of B-type natriuretic peptide (BNP), which is known as prognostic marker for ACS patients, is also worth noting [9]. It is thought that BNP inhibits cardiomyocytes and fibroblasts augmentation, and hinders collagen synthesis not only in connection to cardiac muscle but also periodontal tissues. Moreover, it inhibits synthesis and activity of MMP's, limits neutrophil granulocyte activity and decreases the activity of platelets. BNP level can be increased by factors such as smoking, stress, diabetes and age. These factors are also risk factors in PD [10].
The aim of the paper was to evaluate the state of the oral cavity and test the association between chosen parameters of acute hospital phase MI in patients aged 60 and younger.

\section{Methods}

\section{Case group}

The case group included patients with acute ST elevation MI (STEMI) or acute non-ST-elevation MI (NSTEMI) hospitalized in clinical department of cardiology of the regional cardiology center in 2008-2009. The control group consisted of patients with stable angina (SAP). Inclusion criteria for the case group were: (1) presence of STEMI or NSTEMI; (2) age $\leq 60$; (3) normal coagulation parameters (INR $\leq 1.3$, normal activated partial thromboplastin time; (4) written consent for participation in the study. Exclusion criteria for the case group were: (1) diseases associated with acute or chronic inflammatory process; (2) hepatic or renal failure; (3) cachexia and malnutrition.

\section{Control group}

The main inclusion parameter for the control group was the presence of SAP and main exclusion criteria were ACS or MI. Other inclusion and exclusion criteria were identical as for the case group.

\section{Examination}

In the second day of hospitalization in the course of acute MI, medical history and blood samples for laboratory investigations were taken from the patients, and they were subjected to physical examination.

The Examinations consisted of dental and cardiovascular examination.

Dental examination included dental history (with periodontologic history) and physical dental examination with assessment of the following parameters: (1) the simplified approximal plaque index (API) acc. Lange; (2) clinical attachment loss (CAL); (3) probing depth (PDI); (4) bleeding index (BI) acc. Ainamo and Bay [11]; (5) number of molar teeth.

The 621 WHO perio probe was used for testing. Periodontal research was calibrated appropriately. Among the patients with acute MI group of edentulous patients (34 patients), group with severe periodontitis (46 patients), and group with mild periodontitis (32 patients) were isolated. The patients were qualified to certain groups and advancement of periodontitis was diagnosed according to Classification System for Periodontal Disease and Conditions established at the International 
Workshop and for a Classification of Periodontal Diseases and Conditions held in USA in 1999 [12]. According to the above classification mild periodontitis is characterized with CAL $1-2 \mathrm{~mm}$ and severe periodontitis with CAL $>5$.

General medical examination included medical history and physical examination. Imaging examinations included: electrocardiography, echocardiography, angiography of coronary arteries, ultrasonography of carotid arteries and ankle-brachial index (ABI) measurement. Laboratory tests were used to evaluate CRP, fibrinogen, IL- 6 , TNF- $\alpha$ and BNP concentration in peripheral blood.

Blood samples were taken in the morning from every patient from the case group on an empty stomach, from the ulnar vein, and collected in 4 test tubes.

First test tube was used for CRP marking, which was carried out with immunoturbidimetric method (Olympus AU680, Olympus America Inc, USA). The second one was used to determine fibrinogen. For this purpose $8-10 \mathrm{~mL}$ of district blood was put into the tube containing sodium citrate and centrifuged for $15 \mathrm{~min}(1500 \mathrm{G})$. The marking was carried out in plasma with modified Clauss method (BCS ${ }^{\circledR}$, Dade Behring, Deerfield, IL).

For the purpose of cytokines' marking blood was put into the sterile test tube which was centrifuged for $15 \mathrm{~min}(2500 \mathrm{G})$. Collected serum was frozen and stored in the temperature of $-20^{\circ} \mathrm{C}$ up to the moment of marking. IL- 6 was marked using chemiluminescence method on the ready immunoassay system (Access, Beckman Coulter, Switzerland). TNF- $\alpha$ was indicated using immunoradiometric assay with ready manufacturer's sets (DIAsource Immunoassays S.A., Belgium).

BNP marking was carried out on the serum from blood sample collected into the test tube containing dipotassium EDTA and centrifuged for $15 \mathrm{~min}(2500 \mathrm{G})$. The marking was carried out using chemiluminescence method (DXI 600, Beckman Coulter, Switzerland) with DXI 600 system. Ultrasound examination was performed to evaluate the tunica media and intima-media thickness (IMT), and the number of atherosclerotic plaques in carotid artery. The examination results were recorded in patients individual charts. Research project was approved by the Commission of Bioethics of the Swietokrzyskie Regional Chamber of Physicians and Dentists (approval number 4/2008).

\section{Statistical analysis}

For each quantitative parameter mean values and standard deviations were calculated, and for qualitative parameters differences of the frequency of the occurrence were evaluated. The following tests and methods of the statistical analyses were applied: the t-Student test, the one way analysis of variance (ANOVA), chi-squared test for single classification, Spearman's rank correlation coefficient, logistic regression with the risk factor. Evaluation of statistical significance on the bases of p-value with significance level $\mathrm{p}<0.05$. Calculations were performed on MedCalc Wer. 11.5.1.0. computer program.

\section{Results}

\section{Clinical characteristics of case and control groups}

Table 1 shows clinical characteristics of case and control groups. The study involved $112 \mathrm{pa}-$ tients ( 85 men and 27 women) including 85 patients with STEMI and 27 patients with NSTEMI. Control group consisted of 67 patients with SAP (43 men, 24 women). Mean age of patients was $53 \pm 4$. The proportion of men was higher to women in the group with acute MI (76\%). In patients with acute MI risk factors were more prevalent than in patients with SAP. As much as $85 \%$ of patients in the case group were smokers. The case group in comparison to the control group was characterized by significantly higher prevalence of arterial hypertension $(\mathrm{p}<0.0001)$, higher body mass index $(\mathrm{p}=0.0128)$. The case group was characterized by higher total blood cholesterol ( $p<0.0001)$, triglycerides $(\mathrm{p}<0.0001)$ but lower glomerular filtration rate $(\mathrm{p}=0.0004)$ than the control group. Patients with MI had also significantly higher CRP $(p<0.0001)$ and fibrinogen $(\mathrm{p}<0.0001)$ than patients with SAP.

\section{Results of oral health status assessment including periodontal examination in patients with acute MI and SAP}

In the examined group of patients with acute MI there was a higher intensity of risk factors comparing to the group with stable CAD (Table 1).

There were significant differences in oral health status between patients with acute MI and those with SAP (Table 2). Mean API was higher in the case group ( $72 \%$ ) than in the control group (17\%; $\mathrm{p}<0.0001)$. Mean CAL value was $3.98 \mathrm{~mm}$ in acute MI group and $0.95 \mathrm{~mm}$ in SAP group $(\mathrm{p}<0.0001)$ and PDI was $4.16 \mathrm{~mm}$ and $1.61 \mathrm{~mm}$, respectively $(\mathrm{p}<0.0001)$. BI was significantly higher in the case group $(p=0.003)$. In the case group advanced periodontal disease (APD) and mild periodontal disease (MPD) were present, respectively, in $41 \%$ and $29 \%$ of patients. The prevalence of edentulo- 
Table 1. Clinical characteristics-comparison of mean values (mean \pm SD) of chosen parameters and comparison of frequency in the examined groups.

\begin{tabular}{|c|c|c|c|}
\hline Parameter & $\begin{array}{l}\text { Patients with MI } \\
\text { (case group) } \\
N=112\end{array}$ & $\begin{array}{c}\text { Patients with SAP } \\
\text { (control group) } \\
\mathbf{N}=67\end{array}$ & $\mathbf{P}$ \\
\hline Men & $85(76 \%)$ & $43(64 \%)$ & NS** \\
\hline Women & $27(24 \%)$ & $24(36 \%)$ & \\
\hline Age & $53.4 \pm 6.5$ & $54.6 \pm 9.4$ & NS* \\
\hline Tobacco smoking & $95(85 \%)$ & $28(42 \%)$ & $<0.0001 * *$ \\
\hline History of arterial hypertension & $77(68 \%)$ & $19(20 \%)$ & $<0.0001 * *$ \\
\hline History of diabetes & $38(34 \%)$ & $15(22 \%)$ & $N S^{* *}$ \\
\hline Body mass index $\left[\mathrm{kg} / \mathrm{m}^{2}\right]$ & $28.0 \pm 4.3$ & $26.4 \pm 3.8$ & $0.0128 *$ \\
\hline Systolic blood pressure [mm Hg] & $135.0 \pm 19.7$ & $123.2 \pm 10.4$ & $<0.0001^{*}$ \\
\hline Total cholesterol [mg/dL] & $198.8 \pm 47.2$ & $153.5 \pm 21.8$ & $<0.0001^{*}$ \\
\hline Triglycerides $[\mathrm{mg} / \mathrm{dL}]$ & $184.9 \pm 128.7$ & $92.5 \pm 30.2$ & $<0.0001^{*}$ \\
\hline Glomerular filtration rate $[\mathrm{mL} / \mathrm{min}]$ & $70.2 \pm 18.4$ & $79.0 \pm 16.2$ & $0.0004^{*}$ \\
\hline C-reactive protein $[\mathrm{mg} / \mathrm{dL}]$ & $14.9 \pm 17.7$ & $3.2 \pm 2.3$ & $<0.0001^{*}$ \\
\hline Fibrinogen & $4.8 \pm 1.48$ & $3.3 \pm 0.64$ & $<0.0001^{*}$ \\
\hline
\end{tabular}

$\mathrm{MI}$ - myocardial infarction; SAP — stable angina

Table 2. Chosen parameters of periodontitis in patients with acute myocardial infarction and patients with stable angina - comparison of mean values (mean $\pm \mathrm{SD}$ ).

\begin{tabular}{lccc}
\hline Parameter & $\begin{array}{c}\text { Patients with MI } \\
(\mathbf{n}=\mathbf{7 8})^{*}\end{array}$ & $\begin{array}{c}\text { Patients with SAP } \\
(\mathbf{n}=\mathbf{6 0})^{* *}\end{array}$ & P \\
\hline Aproximal plaque index [\%] & $72.0 \pm 28.2$ & $17.0 \pm 13.0$ & $<0.0001^{*}$ \\
Pocket depth [mm] & $4.2 \pm 2.0$ & $1.6 \pm 0.5$ & $<0.0001^{*}$ \\
Clinical attachment loss [mm] & $4.0 \pm 2.5$ & $1.0 \pm 1.2$ & $<0.0001^{*}$ \\
Bleeding index [\%] & $12.9 \pm 26.3$ & $0.8 \pm 2.8$ & $0.0005^{*}$ \\
\hline
\end{tabular}

$\mathrm{Ml}$ - myocardial infarction; SAP — stable angina; *without the toothless patients: $112-34=78$; ${ }^{*}$ without the toothless patients: $67-7=60 ; p-$ significance level for T-student test

Table 3. Cardiovascular and inflammatory parameters in patients with acute myocardial infarction-comparison of mean values (mean $\pm \mathrm{SD}$ ).

\begin{tabular}{lcccc}
\hline Parameter & $\begin{array}{c}\text { Edentulousness } \\
(\mathbf{n}=\mathbf{3 4})\end{array}$ & $\begin{array}{c}\text { Advanced periodontal } \\
\text { disease }(\mathbf{n}=\mathbf{4 6})\end{array}$ & $\begin{array}{c}\text { Mild periodontal } \\
\text { disease }(\mathbf{n}=\mathbf{3 2})\end{array}$ & $\mathbf{P}$ \\
\hline C-reactive protein $[\mathrm{mg} / \mathrm{L}]$ & $21.5 \pm 22.4$ & $14.2 \pm 17.9$ & $9.2 \pm 7.2$ & 0.0170 \\
Fibrinogen $[\mathrm{g} / \mathrm{L}]$ & $4.9 \pm 1.6$ & $4.6 \pm 1.5$ & $4.6 \pm 1.1$ & $\mathrm{NS}$ \\
Interleukin-6 [pg/mL] & $8.6 \pm 6.0$ & $6.8 \pm 7.3$ & $5.4 \pm 4.4$ & $\mathrm{NS}$ \\
TNF- $\alpha$ [pg/mL] & $15.8 \pm 5.2$ & $19.0 \pm 9.8$ & $18.9 \pm 6.5$ & $\mathrm{NS}$ \\
BNP [pg/L] & $210.7 \pm 473.7$ & $203.3 \pm 327.1$ & $87.9 \pm 58.0$ & NS \\
\hline
\end{tabular}

TNF $\alpha$ - tumor necrosis factor-alpha; BNP — B-type natriuretic peptide; $\mathrm{p}$ - statistical significance level for one-way analysis of variance (ANOVA); NS - not significant

usness was $30 \%$ in the case group and $10 \%$ in the control group.

\section{Result of cardiovascular and inflammatory parameters in patients with MI}

The subgroup with APD and the edentulous subgroup had significantly higher CPR level in comparison to the subgroup with MPD ( $\mathrm{p}=$ $=0.0170$ ). No significant differences were observed in concentrations of fibrinogen, pro-inflammatory cytokines and BNP between the subgroups. However, the parameters in the subgroup with APD were slightly elevated comparing to the subgroup with MPD (Table 3). 
Table 4. Results of imaging examinations in patients with acute myocardial infarction (case group).

\begin{tabular}{lcccc}
\hline Parameter & $\begin{array}{c}\text { Edentulousness } \\
(\mathbf{n}=\mathbf{3 4})\end{array}$ & $\begin{array}{c}\text { Advanced } \\
\text { periodontal } \\
\text { disease }(\mathbf{n}=\mathbf{4 6})\end{array}$ & $\begin{array}{c}\text { Mild periodontal } \\
\text { disease }(\mathbf{n}=\mathbf{3 2})\end{array}$ & $\mathbf{P}$ \\
\hline IMT [mm] & $2.1 \pm 0.8$ & $1.8 \pm 0.9$ & $1.5 \pm 0.7$ & $0.0276^{*}$ \\
$\begin{array}{l}\text { Presence of atherosclerotic } \\
\text { plaques in carotid artery }\end{array}$ & $17(11 \%)$ & $19(21 \%)$ & $8(16 \%)$ & $0.0488^{* *}$ \\
$\begin{array}{l}\text { Ankle-brachial index } \\
\text { Segmental contractility disorders }\end{array}$ & $1.02 \pm 0.1$ & $0.983 \pm 0.1$ & $1.04 \pm 0.2$ & $\mathrm{NS}^{* *}$ \\
Left ventricular ejection fraction & $50.1 \pm 84(85 \%)$ & $44 / 46(95 \%)$ & $28 / 32(85)$ & $\mathrm{NS}^{*}$ \\
\hline
\end{tabular}

IMT — intima-media thickness; ${ }^{*}$ significance level for one way analysis of variance (ANOVA); ${ }^{* *}$ significance level for $\chi^{2}$ test

Table 5. Associations between chosen parameters of periodontitis, teeth number and inflammatory markers in patients with acute myocardial infarction.

\begin{tabular}{|c|c|c|c|c|c|c|}
\hline \multirow{2}{*}{$\begin{array}{l}\text { Inflammatory } \\
\text { markers }\end{array}$} & \multicolumn{6}{|c|}{ Periodontal rates } \\
\hline & API & CAL & PDI & BI & $1-10$ teeth & $>10$ teeth \\
\hline \multicolumn{7}{|l|}{ CRP } \\
\hline $\mathrm{R}$ & 0.217 & 0.283 & 0.210 & 0.181 & -0.334 & -0.0 \\
\hline $\mathrm{p}$ & $<0.05$ & $<0.01$ & $<0.05$ & NS & $<0.05$ & NS \\
\hline \multicolumn{7}{|l|}{ Fibrinogen } \\
\hline $\mathrm{R}$ & 0.273 & 0.261 & 0.204 & 0.105 & 0.276 & 0.283 \\
\hline$p$ & $<0.01$ & $<0.01$ & $<0.05$ & NS & $<0.05$ & $<0.05$ \\
\hline
\end{tabular}

$\mathrm{API}$ - approximal plaque index; CAL — clinical attachment level; PDI — pocket depth; $\mathrm{BI}$ — bleeding index; CRP — C-reactive protein; $\mathrm{R}$ - Spearman correlation coefficient; $\mathrm{p}$ - significance level

Table 4 shows results of imaging studies. IMT was significantly higher in edentulousness subgroup ( $\mathrm{p}=0.0276)$, and atherosclerotic plaques were most common in APD subgroup and in edentulousness subgroup $(\mathrm{p}=0.0488)$. There were no differences in ABI, left ventricular ejection fraction (LVEF) and segmental myocardial contractility disorders between those subgroups.

The influence of periodontitis indexes on inflammable markers was proven (Table 5). The strongest correlation occurred between CRP concentration and CAL, and between fibrinogen concentration and API. The negative correlation between the number of teeth (1-10) and CRP concentration was observed but positive correlation between number of teeth and fibrinogen was noticed.

\section{Association of oral health status parameters with markers of myocardial injury}

Table 6 presents the results of simple logistic regression analysis, which revealed relationships between API, CAL, PDI, BI, edentulousness and creatinine kinase MB (CK-MB), troponins, BNP and LVEF adjusted to the effects of age, gender, status smoking. Concentrations of CK-MB, troponin and BNP were significantly correlated with API, CAL, PDI, and BI. The patients with increased PDI had significantly higher risk of $\mathrm{MI}(\mathrm{OR}=4.22)$. Edentulousness common in the case group was significantly correlated with troponin concentration in those patients. The decrease of LVEF was significantly associated with API, and increased IMT with API and CAL. Edentulous patients had 9-fold increased risk of elevated IMT in comparison to patients with teeth $(\mathrm{OR}=9.29)$.

\section{Discussion}

People with acute MI were characterized by high prevalence of the so-called classic cardiovascular risk factors including: age, sex, tobacco smoking, obesity, lipid abnormalities, hypertension [13]. It should be stressed that some risk factors are common for both PD and CAD. Recent papers suggest that dental plaque which is a primary risk factor for periodontal disease may be associated with CAD [14].

The dominant risk factor in the case group was tobacco smoking. As much as $85 \%$ of patients 
Table 6. Association of oral health status parameters with IMT and markers of myocardial infarction extent

\begin{tabular}{|c|c|c|c|c|c|}
\hline \multirow{2}{*}{$\begin{array}{l}\text { Independent } \\
\text { variables }\end{array}$} & \multicolumn{5}{|c|}{ Dependent variables } \\
\hline & $\begin{array}{l}\text { Troponins } \\
\text { [mg/mL] } \\
\text { (>0.3 vs. } \\
\text { lower) }\end{array}$ & $\begin{array}{c}\text { CK-MB } \\
\text { [mg/mL] } \\
\text { (12 vs. } \\
\text { lower) }\end{array}$ & $\begin{array}{c}\text { BNP } \\
\text { [pg/mL] } \\
\text { (> 100 vs. } \\
\text { lower) }\end{array}$ & $\begin{array}{c}\text { LVEF } \\
{[\%]} \\
\text { (<50 vs. } \\
\text { higher) }\end{array}$ & $\begin{array}{c}\text { IMT } \\
{[\mathrm{mm}]} \\
\text { (> } 0.9 \mathrm{vs} . \\
\text { lower) }\end{array}$ \\
\hline \multicolumn{6}{|l|}{ API [\%] } \\
\hline $\begin{array}{l}\mathrm{OR}^{*}(95 \% \mathrm{Cl}) \\
\mathrm{P} \text { value (OR) }\end{array}$ & $\begin{array}{c}1.06(1.04-2.48) \\
0.0001\end{array}$ & $\begin{array}{c}1.05(1.3-1.07) \\
0.0001\end{array}$ & $\begin{array}{c}4.16(2.22-7.78) \\
0.0010\end{array}$ & $\begin{array}{c}0.97(0.96-0.99) \\
0.0070\end{array}$ & $\begin{array}{c}1.02(1.00-1.04) \\
0.0030\end{array}$ \\
\hline \multicolumn{6}{|l|}{ CAL [mm] } \\
\hline $\begin{array}{l}\mathrm{OR}^{*}(95 \% \mathrm{Cl}) \\
\mathrm{P} \text { value (OR) }\end{array}$ & $\begin{array}{c}1.87(1.41-2.48) \\
0.0001\end{array}$ & $\begin{array}{c}1.48(1.20-1.84) \\
0.0001\end{array}$ & $\begin{array}{c}1.34(1.11-1.62) \\
0.0020\end{array}$ & $\begin{array}{c}0.92(0.77-1.10) \\
\text { NS }\end{array}$ & $\begin{array}{c}1.42(1.09-1.85) \\
0.0090\end{array}$ \\
\hline \multicolumn{6}{|l|}{ PDI [mm] } \\
\hline $\begin{array}{l}\mathrm{OR}^{*}(95 \% \mathrm{Cl}) \\
\mathrm{P} \text { value (OR) }\end{array}$ & $\begin{array}{c}4.22(2.25-7.89) \\
0.0001\end{array}$ & $\begin{array}{c}2.06(1.45-2.92) \\
0.0001\end{array}$ & $\begin{array}{c}1.40(1.11-1.75) \\
0.0030\end{array}$ & $\begin{array}{c}0.83(0.65-1.07) \\
\text { NS }\end{array}$ & $\begin{array}{c}1.33(0.99-1.78) \\
\text { NS }\end{array}$ \\
\hline \multicolumn{6}{|l|}{ BI [\%] } \\
\hline $\begin{array}{l}\mathrm{OR}^{*}(95 \% \mathrm{Cl}) \\
\mathrm{P} \text { value (OR) }\end{array}$ & $\begin{array}{c}1.06(1.00-1.13) \\
0.0390\end{array}$ & $\begin{array}{c}1.02 \text { (0.99-1.04) } \\
\text { NS }\end{array}$ & $\begin{array}{c}1.01(0.99-1.03) \\
\text { NS }\end{array}$ & $\begin{array}{c}0.99(0.97-1.01) \\
\text { NS }\end{array}$ & $\begin{array}{c}1.02(0.98-1.06) \\
\text { NS }\end{array}$ \\
\hline \multicolumn{6}{|l|}{$\begin{array}{l}\text { Edentulousness } \\
(1: \text { YES; 0: NO) }\end{array}$} \\
\hline $\begin{array}{l}\mathrm{OR}^{*}(95 \% \mathrm{Cl}) \\
\mathrm{P} \text { value (OR) }\end{array}$ & $\begin{array}{c}2.78(1.07-7.19) \\
0.0340\end{array}$ & $\begin{array}{c}1.75(0.75-4.08) \\
\text { NS }\end{array}$ & $\begin{array}{c}0.80(0.33-1.93) \\
\text { NS }\end{array}$ & $\begin{array}{c}1.30(0.56-3.00) \\
\text { NS }\end{array}$ & $\begin{array}{c}9.29(1.19-72.13) \\
0.0330\end{array}$ \\
\hline
\end{tabular}

with acute MI were smokers compared to $42 \%$ in the SAP group. Tobacco smoking is one of the risk factors for both PD and CAD [15]. The lack of basic symptoms of periodontitis in smokers like edema and bleeding may mask development of inflammatory process. Hyman et al. [16] showed that smokers suffering from advanced periodontal disease had 8-fold increased risk of CAD and 2 -fold higher risk of stroke. Studies of Tezal et al. [17] revealed 2-fold increased loss of connective tissue attachment in habitual smokers compared to occasional smokers. Smoking cessation significantly improved periodontal status and slowed bone loss in comparison with persons who continue to smoke [18].

Papers of other authors showed, that the presence of at least 3 of 5 factors (abdominal obesity, increased triglicerides, decreased HDL-cholesterol fraction, hypertension and increased fasting glucose) increased the risk of cardiovascular complications. Every element of metabolic syndrome is associated with increased CRP, correlated also with coronary incidents [19]. Our results confirm the data, and show, that patients with acute MI had substantially increased CRP $(14.9 \mathrm{mg} / \mathrm{dL})$ compared to patients with SAP $(3.2 \mathrm{mg} / \mathrm{dL})$. Ridker et al. [20] revealed, that in patients with metabolic syndrome, CRP can be important predictor of cardiovascular complications. Data from the National Health and Nutrition Examination Survey III showed, that poor type II diabetes control could contribute to increased number of periodontitis exacerbations as compared to healthy individuals after controlling their age, tobacco smoking and education level [21]. Similar results are presented in our paper.

PD was more prevalent in patients with acute MI than in control group. It should be emphasized, that no one in the case group had normal oral health status assessed by the dental examination. Poor oral health status, especially PD, possibly had some influence on overall body inflammatory activity and destabilization of atherosclerotic plaques, the main cause of MI. The case group was characterized by increased IMT and more numerous atherosclerotic plaques than patients in the control group. De Stefano et al. [22] showed that patients with PD had 1.25 -fold increased risk of coronary disease, compared to people without the condition. Janket et al. [23] showed that PD increased the risk of coronary disease and stroke, especially in younger patients.

There were significant differences between case and control group in terms of chronic perio- 
dontitis parameters (CAL and PDI, $\mathrm{p}<0.0001)$ and BI $(p=0.003)$. It should be emphasized that gingival pockets with increased depth may form a reservoir for bacteria, enzymes, toxins and metabolites [24]. This can predispose to transfer of periodontal pathogens to distant organs including cardiovascular system. Studies of Zaremba et al. [25] possibly confirm this mechanism as in over $65 \%$ of patients with coexisting $\mathrm{PD}$ and $\mathrm{CAD}$ pathogens of $\mathrm{PD}$ are also present within atherosclerotic plaques. Research of Offenbacher et al. [26] showed that persons with PD and sulcus depth exceeding $4 \mathrm{~mm}$ had elevated CRP and 8-fold increase of CAD risk. Simple logistic regression analyses presented in cited study revealed, that persons with increased depth of gingival pockets had 4 -fold increased risk of $\mathrm{MI}(\mathrm{OR}=4.22)$. Similar results were obtained by Emingli et al. [27], who showed higher prevalence of gingival sulcus depth exceeding $4 \mathrm{~mm}$ in $60 \mathrm{pa}-$ tients with recent MI than in 60 persons with SAP.

In the group with edentulous and severe periodontitis higher CRP concentration was found, but concentrations of fibrinogen, IL- 6 and TNF- $\alpha$ were at similar level (Table 3). It is worth to remark, that edentulousness was present in as much as $30 \%$ of individuals in this relatively young group. It may be possible, that past or present PD with concomitant risk factors had influence on development of inflammation and atherosclerosis in this group of patients. Similar to atherosclerosis, PD develops over many years and untreated PD can cause long-term exposition to bacteria and transient episodes of bacteremia which initiate, support and exacerbate preexisting general process, e.g. atherosclerosis [28]. Furthermore, the increased level of inflammatory parameters may suggest advanced inflammatory process which was caused, as the present study proved, by advancement of periodontitis. Data from medical histories showed, that the main reason for teeth loss was PD. According to the author of the present study, patients with edentulous and advanced PD had considerably elevated IMT and numerous atherosclerotic plaques, which are the features representative for advanced atherosclerosis in this group in comparison to the group of patients with mild PD (Table 4). Similar results were obtained in Inflammation and Carotid Artery Risk for Atherosclerosis Study (ICARAS). Schillinger et al. [29] performed ultrasonographic examination of carotid arteries in 411 patients and demonstrated correlation between atherosclerotic lesions within those arteries and DMFT (decayed, missing, filled teeth). Those results show, that edentulousness may massively increase atherosclerosis development in comparison to non-edentulous persons, independently from their periodontal status. Desvarieux et al. [30] revealed association between number of lost teeth and atherosclerosis within carotid arteries after controlling for age, sex, tobacco smoking, diabetes, arterial hypertension, lipid abnormalities, education level and physical activity.

Lack of significant differences between subgroups in regard to LVEF and segmental contractility disorder may be explained by effective invasive treatment with reperfusion and decrease of infarction area in the case group (Table 4).

In the present study, the evidence of the influence of chosen clinical parameters of periodontitis on inflammatory markers was delivered. The strongest correlation occurred between CAL and CRP concentration, and between API and fibrinogen concentration (Table 5). The results of the research showed that the more severe periodontitis occurs the more advanced is the inflammable process indicated, among others, by CRP concentration.

Bearing in mind limitations of a case-control type studies our paper may deliver some evidence for influence of oral health status on the extent of MI assessed by markers of myocardial injury (CK-MB, troponin) and BNP. The level of those markers was associated with oral hygiene status assessed by API and PDI grade assessed by CAL, PDI and BI. It is worth to mention, that persons with increased depth of gingival pockets had significantly increased risk of $\mathrm{MI}(\mathrm{OR}=4.22)$. Pockets depth and pathogens inhabiting the pockets were associated with inflammatory reaction expressed among others by increased CRP and fibrinogen which can trigger destabilization of atherosclerotic plaque and have influence on the extent and evolution of MI. The presence of this relation may prove hypothesis stating that "the more advanced periodontal disease the more extensive and severe MI". We demonstrated that in subgroup with ADP, CRP concentration had been higher $(14.2 \mathrm{mg} / \mathrm{dL})$ than in the subgroup with mild PD $(9.2 \mathrm{mg} / \mathrm{dL}$; $\mathrm{p}=0.0170$ ). Similar relation was presented by Offenbacher et al. [26].

There was also a significant relationship between troponin concentration and edentulousness which was highly prevalent in the case group. Decrease of LVEF was significantly correlated with oral hygiene status assessed by API. Increase in IMT which is an indicator of subclinical atherosclerosis was significantly correlated with poor oral hygiene and PDI grade assessed by CAL. The authors demonstrated that edentulous patients had 
9-fold increased risk of increased IMT as compared to non-edentulous individuals $(\mathrm{OR}=9.29)$ after adjusting to age, gender, smoking status. Similar results were obtained by Franek et al. [31] who showed that in patients with chronic renal failure IMT was significantly higher in subgroup with APD in comparison to subgroup with MPD.

On the basis of our research we can state that oral health status, especially the status of periodontal tissues, may have significant influence on the occurrence and clinical course of MI. Variability in strength of correlation between cardiologic and periodontologic parameters may be determined by different intensity of inflammatory changes.

\section{Conclusions}

1. Patients with acute MI aged 60 or younger are characterized by the presence of numerous risk factors common for atherosclerosis and periodontal disease including: male sex, tobacco smoking, overweight and obesity, diabetes.

2. Patients with acute MI present with poor oral health status, and notably often with advanced PD and edentulousness.

3. There is a relationship between API, CAL, PDI, BI, edentulousness and the occurrence and extent of MI assessed by blood troponine, CK-MB, BNP and LVEF.

4. Results of the study suggest, that persons with ischemic heart disease and numerous cardiovascular risk factors should be covered by periodontologic prevention service to decrease the occurrence of cardiovascular incidents in those patients.

\section{Conflict of interest: none declared}

\section{References}

1. Losche W. Periodontitis and cardiovascular disease: Periodontal treatment lowers plasma cholesterol. Editorial. South Med J, 2007; 100: 663-664.

2. Accarini R, De Coddy MF. Periodontal disease as a potential risk factor for acute coronary syndromes. Arq Bras Cardiol, 2006; 87: 539-543.

3. Rufail ML, Schenkein PA, Koertge TE et al. Atherogenic lipoprotein parameter in patients with aggressive periodontitis. J Periodont Res, 2007; 42: 495-502.

4. Buhlin K, Gustafson A, Pockley AG et al. Risk factor for cardiovascular disease in in patients with periodontitis. Eur Heart J, 2003; 24: 2099-2107.

5. Yin WH, Chen JW, Jen HL et al. Independent prognostic value of elevated high-sensivity C-reactive protein in chronic heart failure. Am Heart J, 2004; 147:931.

6. Ridker PM, Buring JE, Cook NR et al. C-reactive protein, the metabolic syndrome, and risk of incident cardiovascular events. Circulation, 2003; 107: 391.
7. Bouchard P, Boutouyrie P, D'Aiuto F et al. European workshop in periodontal health and cardiovascular disease consensus document. Eur Heart J, 2010; 12 (suppl. B): B13-B22.

8. Hingorani AD, D'Aiuto F. Chronic inflammation, periodontitis and cardiovascular disease. Oral Dis, 2008; 14: 102-104.

9. De Lemos JA, Peacock WF, McCullough PA. Natriuretic peptides in the prognosis and management of acute coronary syndromes. Rev Cardiov Med, 2010; 11 (suppl. 2): S24-S24.

10. Pandit K, Mukhopadhyay P, Ghosh S, Chowdhury S. Natriuretic peptides: Diagnostic and therapeutic use. Indian J Endocrinol Metab, 2011; 15 (suppl. 4): S345-S353.

11. Ainamo J, Bay I. Problems and proposals for recording gingivitis and plaque. Int Dent J, 1975; 25: 229-235.

12. Armitage GC. Development of a classification system for periodontal diseases and conditions. Ann Periodontol, 1999; 4: 1-6.

13. Accarini R, De Coddy MF. Periodontal disease as a potential risk factor for acute coronary syndromes. Arq Bras Cardiol, 2006; 87: 539-543.

14. Tezal M, Scannpieco FA. Wactawski-Wende J, Grossi SG. Supragingival plaque may modify the effect of gingival bacteria on attachment loss. J Perodontol, 2006; 5: 808-813.

15. Zhang W, Fang M, Song F et al. Effects of cigarette smoke condensate and nicotine on human gingival fibroblast-mediated collagen degradation. J Periodontol, 2011; 82: 1071-1079.

16. Hyman JJ, Winn DN, Reid BC. The role cigerette smoking in the association between periodontal disease and coronary heart disease. J Periodontol, 2002; 73: 988-994.

17. Tezal M, Scannpieco FA, Wactawski-Wende J, Grossi SG. Supragingival plaque may modify the effect of gingival bacteria on attachment loss. J Perodontol, 2006; 5: 808-813.

18. Albandar JM, Streckfus CF, Adesnaya MR et al. Cigar, pipe and cigarette smoking as risk factors for periodontal disease and tooth loos. J Periodontol, 2000; 12: 1874-1881.

19. Cao JJ, Arnold AM, Manolio TA et al. Association of carotid artery intima-media thickness, plaques and C-reactive protein with future cardiovascular disease and allcause mortality: The Cardiovascular Health Study. Circulation, 2007; 116: 32-38.

20. Ridker PM, Buring JE, Cook NR et al. C-reactive protein, metabolic syndrome, and risk of incident cardiovascular events. Circulation, 2003; 107: 391.

21. De Simone G, Devereux RB, Chinali M et al. Prognostic impact of metabolic syndrome by different definitions in a population with high prevalence of obesity and diabetes: the Strong Heart Study. Diabetes Care, 2007; 30: 1851-1856.

22. De Stefano, Anda RF, Kahn HS et al. Dental disease and risk of coronary heart disease and mortality. Br Med, 1993; 306: 688-691.

23. Janket SJ, Baird AE, Chuang SK et al. Meta-analysis of periodontal disease and risk of coronary heart disease and stroke. Oral Surg. Oral Med. Oral Pathol. Oral Radiol En-Dod, 2003; 95: 559-569.

24. Silva TA, Garlet GP, Fukada SY et al. Chemokines in oral inflammatory disease: Apical periodontitis and periodontal disease. J Dent Res, 2007; 86: 306-319.

25. Zaremba M, Górska R, Suwalski P. Assessment of the incidence of bacteria associated with periodontal disease in atherosclerotic coronary artery plaque [in Polish]. Czas Stom, 2005; 58: 293-301.

26. Offenbacher S, Elter RJ, Lin D et al. Evidence for periodontitis as tertiary vascular infection. J Internat Acad Periodontol, 2005; 7: 39-48.

27. Emingli G, Buduneli E, Aliyev A et al. Association between periodontal disease and acute myocardial infarction. J Periodontol, 2000; 71: 1882-1886.

28. Beck DJ, Offenbacher S, Williams R. Periodontitis. A risk factor coronary heart disease? Ann Periodontol, 1998; 3: 127-141.

29. Schillinger T, Kluger W, Exner et al. Dental and periodontal status and risk for athero-sclerosis: The inflammation and carotid artery study dental study. Stroke, 2006; 37: 2271-2276.

30. Desvarieux M, Demmer RT, Rundek T et al. Relationship between periodontal disease, tooth loos and coronary artery plaque: The Oral and Vascular Disease Epidemiology Study (INVEST). Stroke, 2003; 34: 2120-2125.

31. Franek E, Blaschyk R, Kolonko A et al. Chronic periodontitis in hemodialysis patients with chronic kidney disease is associated with elevated serum C-reactive protein con-centration and greater intima-media thickness of the carotid artery. J Nephrol, 2006; 19: $346-351$. 